\title{
Optimal Triangular Partially Balanced Incomplete Block Designs for Complete Diallel Cross
}

\author{
Birhanu Woldeyohanes ${ }^{1} \quad$ Professor M.K.Sharma ${ }^{2} \quad$ Associate professor Mekonnen Tadesse ${ }^{3}$ \\ Addis Ababa University, Department of Statistics, Addis Ababa, Ethiopia
}

\begin{abstract}
It is well known that complete diallel cross system IV and triangular partially balanced incomplete block designs have one to one correspondence. In the present paper, we have identified some triangular partially balanced incomplete block designs which generates two types of optimal incomplete block designs for complete diallel cross system IV.(i)The first type is with minimal number of experimental units in proper and non-proper setting for estimating the general combining ability (gca) effects of lines (ii)the second types is with minimum number of experimental units in proper setting for estimating general combining ability (gca) ) effects of lines in presences of specific combining ability (sca)
\end{abstract}

Keywords: Triangular partially balanced incomplete block design, complete diallel cross, General combining ability, of Specific combining ability, optimality

DOI: $10.7176 / \mathrm{JAAS} / 68-03$

Publication date:September $30^{\text {th }} 2020$

\section{INTRODUCTION}

Diallel crossing is a very useful method for conducting plant and animal breeding experiments, especially for estimating combining ability effects of lines. Suppose there are $p$ inbred lines and it is desired to perform a diallel crossing experiments involving $p(p-1) / 2$ crosses of the type (ixj) $=(j x i)$ for $i \neq j=1,2, \ldots, p$. This is a complete diallel cross system IV mating design of Griffing (1956), who studied the detailed analysis of such mating designs laid out in a randomized complete block design. Henceforth, we will call it Complete Diallel Crosses (CDC).

Optimal block designs for CDC have been considered by Gupta and Kageyama (1994), Dey and Midha (1996), Das et.al (1998), Parsadet al(1999), Sharma (2004), Parsadet al(2005) and Sharma and Fanta (2010) by using nested incomplete (NBIB) designs, triangular PBIB design nested balanced block(NBB) designs circular designs and PBIB designs for the cas where the model includes general combining ability(gca) effects apart from block effects but no specific combing ability (sca) effects.

Chai and Mukerjee(1999) considered the case when sca effects are also present in the model and showed that the triangular designs thar=t are proved to be optimal for gcs comparison by Dey and Midha(1996) and Das.et.al(1998) remain optimal for gca comparison even sca effects are presents in the model. Das.et.al (1998) stated a condition in theorem 4.1 on page 334 for a block designs for CDC derived from a triangular designs to be universally optimal. Chai.et al.(2002) proved that the optimal designs for CDC given by Guota and Kegeyama(1994) andDas et.al(1998), among the others for gca comparisons are also optimal in presence of sca effects even though that are not triangular designs.

The objective of the present paper is to identify triangular designs which can be used to construct optimal incomplete block designs for CDC with Minimum number of experimental units from catalogue of Clatworthy (1973) and not listed by Dey and Midha (1996), Parsad and Gupta (2004), Das.et al (1998) and Sharma and Fanta (2010). In this investigation we have identified some TPBIB design which can generate optimal incomplete block designs for CDC experiments in proper and non proper settings with minimal number of experimental units for estimating the general combining ability (gca) effects of lines and also can generate optimal incomplete block designs for CDC experiment in proper settings for estimating the gca of lines in presence of specific combing ability. Those designs do not obey the condition given by by Das et. al(1998). The block design in proper and nonproper setting are found universally optimal in sense Kiefer (1975) for estimating the gca effects of lines for CDC experiments. In addition, to the block effects and gca, the model also include sca.

\section{METHOD OF CONSTRUCTION}

Our method of construction of IBD for CDC experiment is essentially the same as that of Agarwal and Das (1987) and Dey and Midha (1996) but with some difference. That is those authors put crosses in original blocks of the TPBIB designs but we have taken the crosses in block as block of the mating designs.

Assume that there are $p$ inbred lines and it is desired to find an IBD design for a mating design involving $p(p-$ 1) $/ 2$ crosses. Consider a two associate triangular PBIB design $d_{1}$ as auxiliary design with parameters $v=p(p-1) / 2$, $\mathrm{b}, \mathrm{r}, \mathrm{k}=\mathrm{b}-1, \lambda_{1}, \lambda_{2}, \mathrm{n}_{1}, \mathrm{n}_{2}, p_{j k}^{i}$ for $\mathrm{i}, \mathrm{j}, \mathrm{k}=1,2$. The treatments of the design $\mathrm{d}_{1}$ are indexed by a pair (ixj) for $\mathrm{i}<\mathrm{j}$, $\mathrm{i}, \mathrm{j},=1,2, \ldots, \mathrm{p}$.

Two treatments, say $(\alpha, \beta)$ and $(\gamma, \delta)$, are first associates if ether $\alpha=\gamma, \beta \neq \delta$, or $\alpha \neq \delta, \beta=\gamma$; they are second 
associates or $\alpha \neq \delta, \beta=\gamma$; they are second associates otherwise. from the design $\mathrm{d}_{1}$, we derived a block design, say $\mathrm{d}_{2}$ by replacing a treatment in $\mathrm{d}_{1}$ by cross(ixj) for $\mathrm{I}<\mathrm{j}, \mathrm{I}, \mathrm{j}=1,2, \ldots, \mathrm{p}$. Clearly $\mathrm{d}_{2}$ involves $\mathrm{p}(\mathrm{p}-1) / 2$ crosses, $\mathrm{b}$ blocks each of size k-1. Each cross is replicated $r$ times. Now in $\mathrm{d}_{2}$ we interchange the position of the blocks and block size, that is, now we have a design $\mathrm{d}_{3}$ with parameters $\mathrm{v}=\mathrm{p}(\mathrm{p}-1) / 2, \mathrm{~b}^{\prime}=\mathrm{k}-1, \mathrm{k}^{\prime}=\mathrm{b}, \mathrm{r}$. When $\mathrm{p}$ is odd, design $\mathrm{d}_{3}$ can be divided into two same IBD $d$ with parameters $v=p(p-1) / 2, b^{\prime \prime}=(k-1) / 2, k^{\prime \prime}=b, r=1$. Similarly when $\mathrm{p}$ is even, design $\mathrm{d}_{3}$ can be divided into two same IBD design $\mathrm{d}^{*}$ with parameters $\mathrm{v}=\mathrm{p}(\mathrm{p}-1) / 2, \mathrm{~b}^{\prime \prime \prime}=(\mathrm{k}-$ $1) / 2, \mathbf{k}^{\prime \prime \prime}=(b, b, \ldots, b / 2), r=1$ The method of construction is illustrated below for both cases when $p$ is odd (even).

Example 2.1: Let $p=5$, we take the following ordered 10 crosses indexed as given below.

\begin{tabular}{|l|l|l|l|l|l|l|l|l|l|}
\hline 1 & 2 & 3 & 4 & 5 & 6 & 7 & 8 & 9 & 10 \\
\hline $1 \times 2$ & $1 \times 3$ & $1 \times 4$ & $1 \times 5$ & $2 \times 3$ & $2 \times 4$ & $2 \times 5$ & $3 \times 4$ & $3 \times 5$ & $4 \times 5$ \\
\hline
\end{tabular}

Now we consider a triangular PBIB design $\mathrm{d}_{1}(\mathrm{~T} 28$, Clatworthy, 1973) with parameters $\mathrm{v}=10, \mathrm{~b}=5, \mathrm{k}=4, \mathrm{r}=2$, $\lambda_{1}=1, \lambda_{2}=0$. From design $\mathrm{d}_{1}$, a mating design $\mathrm{d}_{2}$ for diallel crossing can be obtained by replacing each treatment with the cross corresponding to $\mathrm{i}^{\text {th }}$ treatment, we get the required mating design for CDC.

\begin{tabular}{|c|c|c|c|c|c|c|c|c|}
\hline $\mathrm{B}_{1} \quad 1$ & 2 & 3 & 4 & $\mathrm{~B}_{1}$ & $1 \times 2$ & $1 \times 3$ & $1 \times 4$ & $1 \times 5$ \\
\hline $\mathrm{B}_{2} 5$ & 6 & 7 & 1 & $\mathrm{~B}_{2}$ & $2 \times 3$ & $2 \times 4$ & $2 \times 5$ & $1 \times 2$ \\
\hline $\mathrm{B}_{3} 8$ & 9 & 2 & 5 & $\mathrm{~B}_{3}$ & $3 \times 4$ & $3 \times 5$ & $1 \times 3$ & $2 \times 3$ \\
\hline $\mathrm{B}_{4} 10$ & 3 & 6 & 8 & B4 & $4 \times 5$ & $1 \times 4$ & $2 \times 4$ & $3 \times 4$ \\
\hline $\mathrm{B}_{5} 4$ & 7 & 9 & 10 & $\mathrm{~B}_{5}$ & $1 \times 5$ & $2 \times 5$ & $3 \times 5$ & $4 \times 5$ \\
\hline
\end{tabular}

Now consider columns of $d_{2}$ as blocks, we get design $d_{3}$ for CDC experiment system $\mathrm{d}_{3}$

$\mathrm{B}_{1} \quad \mathrm{~B}_{2} \quad \mathrm{~B}_{3} \quad \mathrm{~B}_{4}$

$\begin{array}{llll}1 \times 2 & 1 \times 3 & 1 \times 4 & 1 \times 5\end{array}$

$\begin{array}{llll}2 \times 3 & 2 \times 4 & 2 \times 5 & 1 \times 2\end{array}$

$3 \times 4 \quad 3 \times 5 \quad 1 \times 3 \quad 2 \times 3$

$4 \times 5 \quad 1 \times 4 \quad 2 \times 4 \quad 3 \times 4$

$1 \times 5 \quad 2 \times 5 \quad 3 \times 5 \quad 4 \times 5$

\begin{tabular}{cccc}
$\mathrm{d}$ & \multicolumn{3}{c}{$\mathrm{d}$} \\
$\mathrm{B}_{1}$ & $\mathrm{~B}_{2}$ & $\mathbf{B}_{3}$ & $\mathbf{B}_{4}$ \\
$1 \times 2$ & $1 \times 3$ & $1 \times 4$ & $1 \times 5$ \\
$2 \times 3$ & $2 \times 4$ & $2 \times 5$ & $1 \times 2$ \\
$3 \times 4$ & $3 \times 5$ & $1 \times 3$ & $2 \times 3$ \\
$4 \times 5$ & $1 \times 4$ & $2 \times 4$ & $3 \times 4$ \\
$1 \times 5$ & $2 \times 5$ & $3 \times 5$ & $4 \times 5$
\end{tabular}

Thus we get IBD for CDC experiment with parameters $\mathrm{v}=10, \mathrm{~b}^{\prime}=4, \mathrm{k}^{\prime}=5, \mathrm{r}=2$. By observing the above design we find that it can be divided into two same IBD designs $\mathrm{d}$ where blocks have been designated in italic and bold letters, for CDC experiment having parameters $\mathrm{v}=10, \mathrm{~b}^{\prime \prime}=2, \mathrm{k}^{\prime \prime}=5$, and $\mathrm{r}=1$.

Example 2.2: Let $\mathrm{p}=6$, we take the following ordered 15 crosses

\begin{tabular}{|l|l|l|l|l|l|l|l|l|l|l|l|l|l|l|}
\hline $1 \times 2$ & $1 \times 3$ & $1 \times 4$ & $1 \times 5$ & $1 \times 6$ & $2 \times 3$ & $2 \times 4$ & $2 \times 5$ & $2 \times 6$ & $3 \times 4$ & $3 \times 5$ & $3 \times 6$ & $4 \times 5$ & $4 \times 6$ & $5 \times 6$ \\
\hline 1 & 2 & 3 & 4 & 5 & 6 & 7 & 8 & 9 & 10 & 11 & 12 & 13 & 14 & 15 \\
\hline
\end{tabular}

Now we take triangular design $\mathrm{d}_{1}$ (T48, Clatworthy, 1973) with parameters $\mathrm{v}=15, \mathrm{~b}=6, \mathrm{r}=2, \mathrm{k}=5, \lambda_{1}=1, \lambda_{2}=0$. From this design, a mating design $\mathrm{d}_{2}$ for CDC can be obtained by replacing each $\mathrm{i}^{\text {th }}$ treatment corresponding $\mathrm{i}^{\text {th }}$ cross. We get the required mating design for CDC. Now consider columns of mating design as blocks, we get design $\mathrm{d}_{3}$ for CDC experiment.

$\mathrm{d}_{1}$

$\begin{array}{lllccc}\mathrm{B}_{1} & 1 & 2 & 3 & 4 & 5 \\ \mathrm{~B}_{2} & 6 & 7 & 8 & 9 & 1 \\ \mathrm{~B}_{3} & 10 & 11 & 12 & 2 & 6 \\ \mathrm{~B}_{4} & 13 & 14 & 3 & 7 & 10 \\ \mathrm{~B}_{5} & 15 & 4 & 8 & 11 & 13 \\ \mathrm{~B}_{6} & 5 & 9 & 12 & 14 & 15\end{array}$

$\mathrm{d}_{2}$

$\begin{array}{llllll}\mathrm{B}_{1} & 1 \times 2 & 1 \times 3 & 1 \times 4 & 1 \times 5 & 1 \times 6 \\ \mathrm{~B}_{2} & 2 \times 3 & 2 \times 4 & 2 \times 5 & 2 \times 6 & 1 \times 2 \\ \mathrm{~B}_{3} & 3 \times 4 & 3 \times 5 & 3 \times 6 & 1 \times 3 & 2 \times 3 \\ \mathrm{~B}_{4} & 4 \times 5 & 4 \times 6 & 1 \times 4 & 2 \times 4 & 3 \times 4 \\ \mathrm{~B}_{5} & 5 \times 6 & 1 \times 5 & 2 \times 5 & 3 \times 5 & 4 \times 5 \\ \mathrm{~B}_{6} & 1 \times 6 & 2 \times 6 & 3 \times 6 & 4 \times 6 & 5 \times 6\end{array}$

Now consider columns of design $\mathrm{d}_{2}$ as blocks, we get design $\mathrm{d}_{3}$ for CDC experiment.

$$
\mathrm{d}_{3}
$$

\begin{tabular}{rccccc}
$\mathrm{B}_{1}$ & $\mathrm{~B}_{2}$ & $\mathrm{~B}_{3}$ & $\mathrm{~B}_{4}$ & $\mathrm{~B}_{5}$ \\
$1 \times 2$ & $1 \times 3$ & $1 \times 4$ & \multicolumn{2}{c}{$1 \times 5$} & $1 \times 6$ \\
$2 \times 3$ & $2 \times 4$ & $2 \times 5$ & $2 \times 6$ & $1 \times 2$ & \\
$3 \times 4$ & $3 \times 5$ & $3 \times 6$ & $1 \times 3$ & $2 \times 3$ & \\
$4 \times 5$ & $4 \times 6$ & $1 \times 4$ & $2 \times 4$ & $3 \times 4$ & \\
$1 \times 6$ & $2 \times 6$ & $3 \times 6$ & $4 \times 6$ & $5 \times 6$ & \\
$5 \times 6$ & $1 \times 5$ & $2 \times 5$ & $3 \times 5$ & $4 \times 5$ &
\end{tabular}

Thus we get IBD for CDC experiment with parameters $\mathrm{v}=15, \mathrm{~b}^{\prime}=6, \mathrm{k}^{\prime}=5, \mathrm{r}=2$. By observing the above design we find that it can be divided into two same IBD designs in non proper setting for CDC experiment having parameters $\mathrm{v}=15, \mathrm{~b}^{\prime \prime \prime}=3, \mathbf{k}^{\prime \prime \prime}=(6,6,3)$, and $\mathrm{r}=1$ as given below. We will denote both designs by $\mathrm{d}^{*}$. 


\begin{tabular}{lcclll} 
& $\mathrm{d}^{*}$. & & \multicolumn{3}{c}{$\mathrm{d}^{*}}$. \\
$\mathrm{B}_{1}$ & $\mathrm{~B}_{2}$ & $\mathrm{~B}_{3}$ & $\mathrm{~B}_{1}$ & $\mathrm{~B}_{2}$ & $\mathrm{~B}_{3}$ \\
$1 \times 2$ & $1 \times 3$ & $1 \times 4$ & $1 \times 4$ & $1 \times 5$ & $1 \times 6$ \\
$2 \times 3$ & $2 \times 4$ & $2 \times 5$ & $2 \times 5$ & $2 \times 6$ & $1 \times 2$ \\
$3 \times 4$ & $3 \times 5$ & $3 \times 6$ & $3 \times 6$ & $1 \times 3$ & $2 \times 3$ \\
$4 \times 5$ & $4 \times 6$ & & & $2 \times 4$ & $3 \times 4$ \\
$5 \times 6$ & $1 \times 5$ & & & $3 \times 5$ & $4 \times 5$ \\
$1 \times 6$ & $2 \times 6$ & & & $4 \times 6$ & $5 \times 6$
\end{tabular}

So we get three types of design for CDC experiments (i) with equal block size and having 2 replications for each cross.(ii) with equal block size and having one replication for each cross.(iii) with unequal block size and having one replication for each cross. The first two are proper setting and the third is non proper setting.

Now we give below the theorem of Choi et.al (2002) which establishes that the design $\mathrm{d} 3$ and $\mathrm{d}$ are optimal for the estimation of gca comparison in presence of sca effects in the model. It is important to note that the design $\mathrm{d}$ is balanced for gca comparisons but not balanced for sca comparison because each cross is replicated only once in each design $d$ that is $r_{c}=1$. It means that all sca comparisons are not steamtable.

Theorem 2.1: considering a binary diallel cross design $D$ with parameters $v=p(p-1) / 2, r_{c}, b$, $k$ such that it is orthogonally blocked with respect to lines, that is each lines occirs in every block r/b times, that is $r=\operatorname{rc}(p-1)$ is the constant number of replication of each the lines. The $=n \mathrm{D}$ is optimal for the estimation of gca comparisons even in the presence of sca effects in the model. According to the above theorem, the design $\mathrm{d} 3$ and $\mathrm{d}$ are orthogonally blocked with respect to the lines, hence optimal for gca comparison in the presence of sca effects in the model. Now we state the following theorem.

Theorem 2.2: for a positive prime $\mathrm{p}>3$, if there exists a two associates triangular PBIB design with parameters $\mathrm{v}=\mathrm{p}(\mathrm{p}-1) / 2, \mathrm{~b}, \mathrm{r}, \mathrm{k}=\mathrm{b}-1, \lambda_{1}, \lambda_{2}, \mathrm{n}_{1}, \mathrm{n}_{2}$ for $\mathrm{i} \mathrm{j},=12$, then there is always exist binary CDC design $\mathrm{d} 3$ with the parameters $\quad \mathrm{v}=\mathrm{p}(\mathrm{p}-1) / 2, \mathrm{~b}-\mathrm{p}-1, \mathrm{k}=\mathrm{p}$ and $\mathrm{r}=2$. Then $\mathrm{d} 3$ is universally optimal for the estimation of gca comparisons even in the presence of sca effects in the model.

Note: Sharma and Fanta (2010) envisaged 85 PBIB designs (Clatworthy ,1973) to construct optimal block designs for CDC experiments. Out of which 20 and 29 PBIB design gave optimal block design for CDC experiments in which cross is replicated once and twice, respectively. The 29 blocks designs are optimal for gca comparison in the presence of sca effects according to theorem 2.1

In net section we give the method of analysis of the design $d_{3}$

\section{ANALYSIS OF DESIGN D}

For the analysis of data obtained from $d_{3}$, we will follow Sing and(Hinklemann's(1998) two stage procedure for estimating gca and sca effects. The first stage is to consider the proposed design for estimation of the effects say $=(\boldsymbol{\tau}, \ldots, \boldsymbol{\tau} \mathrm{p}(\mathrm{p}-1) / 2)^{\prime}$ for design $\mathrm{d}_{3}$ by the following model

$$
\mathbf{Y}=\boldsymbol{\mu} \mathbf{1}_{\mathbf{n}}+\mathbf{X} \boldsymbol{\tau}+\mathbf{D} \boldsymbol{\beta}+\mathbf{e}
$$

Where $\mathbf{Y}$ is the $\mathrm{nx} 1$ vector observations, $\mathbf{1}$ is the $\mathrm{nx} 1$ vectors of ones, $\mathbf{X}$ is the $\mathrm{nxv}$ design matrix for treatments and $\mathbf{D}$ is an nxb design matrix for blocks, that is, the $(h, u)^{\text {th }}\left((\mathrm{h}, \mathrm{i})^{\text {th }}\right.$ elements of $\mathbf{X}($ respectively, of $\mathbf{D})$ is 1 if the $\mathrm{h}^{\text {th }}$ observations pertains to the $\mathrm{u}^{\text {th }}$ cross (to $\mathrm{i}^{\text {th }}$ block), and is zero otherwise $(\mathrm{h}=1, \ldots, \mathrm{n} ; \mathrm{u}=1, \ldots, \mathrm{v} ;$ and $1, \ldots, \mathrm{b}), \boldsymbol{\mu}$ is a general mean, $\boldsymbol{\tau}$ is a $\mathrm{v} \times 1$ vector of treatment parameters, $\boldsymbol{\beta}$ is $\mathrm{a} b \times 1$ vector of block parameters and $\mathbf{e}$ is an $\mathrm{n}$ $\times 1$ vector of residuals. It is assumed that vector $\boldsymbol{\beta}$ is fixed and $\mathbf{e}$ is normally distributed with $\mathrm{E}(\mathbf{e})=0, \mathrm{~V}(\mathbf{e})=\delta^{2} \mathbf{I}$, where $\mathbf{I}$ is the identity matrix of conformable order.

Following Tocher (1952), Raghava Rao(1971), Dey(1986), the least square method for the analysis of a proposed design leads to the following reduced normal equations for the crosses for model (3.1).

$\mathbf{C}_{\mathrm{d}} \boldsymbol{\tau}=\mathbf{Q}_{\mathrm{d}}$

Where $\mathbf{C}_{\mathrm{d}}=\mathbf{R}-\mathbf{N K}^{-1} \mathbf{N}^{\prime}$ and $\mathbf{Q}_{\mathbf{d}}=\left(\mathrm{Q}_{1 \mathrm{~d}}, \ldots, \mathrm{Q}_{\mathrm{vd}}\right)=\mathbf{T}-\mathbf{N} \mathbf{K}^{-1} \mathbf{B}$

In the above expressions above, $\mathbf{R}$ and $\mathbf{K}$ are diagonal matrices of order $\mathbf{v} \times \mathbf{v}$ and $\mathrm{b} \times \mathrm{b}$ with common diagonal elements 2 and $\mathrm{p}$ in the diagonal, respectively. $\mathbf{N}=\mathbf{X}^{\prime} \mathbf{D}$ is

the $\mathrm{v} \times \mathrm{b}$ incidence matrix of the designs $\mathrm{d} ; \mathbf{T}=\mathbf{X}^{\prime} \mathbf{Y}$ and $\mathbf{B}=\mathbf{D}^{\prime} \mathbf{Y}$ are vector of cross totals and block totals of order $\mathrm{v} \times 1$ and $\mathrm{b} \times 1$ respectively for design $\mathrm{d}$.

Hence a solution to (3.2) is given by $\hat{\boldsymbol{\tau}}=\boldsymbol{C}_{\boldsymbol{d}}^{-} \mathbf{Q}_{\mathbf{d}}$

Where $\mathbf{C}_{\mathbf{d}}^{-}$is the generalized inverse of $\mathrm{C}_{\mathrm{d}}$ with the property that $\boldsymbol{C} \boldsymbol{C}^{-\mathbf{1}} \mathbf{C}=\mathbf{C}$. The sum of squares due to crosses are $\boldsymbol{Q}_{\boldsymbol{d}}^{\prime} \boldsymbol{C}_{\boldsymbol{d}}^{-} \boldsymbol{Q}_{\boldsymbol{d}}$ with degree of freedom (d.f) = rank $\left(\mathbf{C}_{\mathrm{d}}\right)$ for design d with expectation and variance of $\mathbf{Q}_{\mathrm{d}}$ being $\mathrm{E}\left(\mathbf{Q}_{\mathrm{d}}\right)=\mathrm{C}_{\mathrm{d}} \tau \quad \operatorname{Var}\left(\mathbf{Q}_{\mathrm{d}}\right)=\boldsymbol{\sigma}^{2} \boldsymbol{C}_{\boldsymbol{d}}$

Now, we will utilize the above equation to estimate the genetics parameters in the proposed design. The second stage is to utilize the fact that the cross effects can be expressed in terms of gca and sca. So we can write effects as follow.

$$
\boldsymbol{\tau}_{\boldsymbol{i j}}=\mathrm{g}_{\mathrm{i}}+\mathrm{g}_{\mathrm{j}}+\mathrm{s}_{\mathrm{ij}}
$$


Where $g_{i}\left(g_{j}\right)$ is the gca for the $i^{\text {th }}\left(j^{\text {th }}\right)$ parent,$s_{i j}\left(s_{i j}=s_{j i}\right)$ is the sca for cross between the $i^{\text {th }}$ and the $j^{\text {th }}$ parent $(i<j=$ $0,1, \ldots, \mathrm{p}-1)$ and we also assume that, $\sum_{i} g_{i}=0$, and $\sum_{j} s_{i j}=\mathrm{o}$. for all i.

In matrix notation equation (3.5) can be written as $=\mathbf{\tau}=\mathbf{Z g}+\mathbf{s}$

Where $\mathrm{Z}\left(\mathrm{z}_{\mathrm{ui}}\right)(\mathrm{u}=1,2, \ldots, \mathrm{v}: \mathrm{i}=0.1, \ldots, \mathrm{p}-1)$ is the cross and gca relation matrix

$\mathrm{Z}_{\mathrm{ui}}=2$ if the $\mathrm{u}^{\text {th }}$ cross has both parents

$=1$ if the $\mathrm{u}^{\text {th }}$ cross has only on parent

$=0$, otherwise

Following the approached used in Kepthorne and Curnow (1961), equation (3.2)can be written as $\mathbf{C}_{\mathbf{d}} \boldsymbol{\tau}=\mathbf{C}_{\mathbf{d}} \mathbf{Z g}$ $\mathrm{C}_{\mathrm{d}} \mathrm{S}$

That is, $\mathrm{E}\left(\mathbf{Q}_{\mathbf{d}}\right)=\mathbf{C}_{\mathbf{d}} \mathbf{Z g} \mathbf{C}_{\mathbf{d}} \mathbf{S}$

Since the matrix $\mathbf{C}$ is singular, we use unified theory of least square due to Rao(1973, page ,300). So estimator of $\mathbf{g}$ is

$\hat{\mathrm{g}}=\left(\boldsymbol{Z}^{\prime} \boldsymbol{C}_{\boldsymbol{d}} \boldsymbol{C}_{d}^{-} \boldsymbol{C}_{\boldsymbol{d}} \boldsymbol{Z}\right)^{-} \boldsymbol{Z}^{\prime} \boldsymbol{Q}_{\boldsymbol{d}}=\left(\boldsymbol{Z}^{\prime} \boldsymbol{C}_{d} \boldsymbol{Z}\right)^{-} \boldsymbol{Z}^{\prime} \boldsymbol{Q}_{\boldsymbol{d}}$

Here the matrix $\left(\mathbf{Z}^{\prime} \mathbf{C}_{\mathrm{d}} \mathbf{Z}\right)=1 / 2(\mathrm{p}-2)\left[\mathbf{I}_{\mathrm{p}}-\frac{\mathbf{1} p \mathbf{1}^{\prime} p}{P}\right]$

Hence trace $\left(\mathbf{Z}^{\prime} \mathbf{C}_{\mathbf{d}} \mathbf{Z}\right)=2(\mathrm{p}-1)(\mathrm{p}-2)$

So $\widehat{g}=1 / 2(\mathrm{p}-2) \mathbf{Z}^{\prime} \mathbf{C} \boldsymbol{\tau}$

Hence $\widehat{\boldsymbol{g}}=\mathbf{H}_{1} \boldsymbol{\tau}$, where $\mathbf{H}_{\mathbf{1}}=1 / 2(\mathrm{p}-2) \mathbf{Z}^{\prime} \mathbf{C}_{\mathbf{d}}$

Now, $\operatorname{var}(\widehat{\boldsymbol{g}})=\mathbf{H}_{1} \boldsymbol{C}^{-} \mathbf{H}_{1} \boldsymbol{\sigma}^{2}=1 / 2(\mathrm{p}-2) \mathbf{I}_{\mathrm{p}} \sigma^{2}$

general combining ability. We thus have the following result.

Theorem 3.1: for positive prime $\mathrm{p}>3 \mathrm{~m}$ if there exists a two associates triangular PBIB with parameters $\mathrm{v}=\mathrm{p}(\mathrm{p}-$ 1)/2,b r,k $=\mathrm{b}-1, \lambda_{1}, \lambda_{2}, \mathrm{n}_{1}, \mathrm{n}_{2}, P_{j k}^{i}$ for $\mathrm{k}=1,2$, then there always exists variance-balanced CDC design with the parameters, $\mathrm{v}=\mathrm{p}(\mathrm{p}-1) / 2, \mathrm{~b}=\mathrm{p}-1, \mathrm{k}=\mathrm{p}$, and $\mathrm{r}=2$ for the estimation of gca comparisons.

Now, substituting the estimate of $\mathbf{g}$ in equation (3.6), we obtain the estimator of $\mathbf{s}$, namely insertion of solution of equation (3.10).

$$
\begin{aligned}
& \hat{s}=\left(C_{d}^{-}-\mathbf{1} / \mathbf{2}(p-\mathbf{2}) Z Z^{\prime}\right) Q_{d}=\left(C_{d}^{-}-\mathbf{1} / \mathbf{2}(p-\mathbf{2}) Z Z^{\prime}\right) C_{\mathrm{d}} \tau=\mathrm{H}_{2} \tau \\
& \text { Where } \mathbf{H 2}=\left(C_{d}^{-}-\mathbf{1} / \mathbf{2}(p-\mathbf{2}) Z Z^{\prime}\right) C_{d} \\
& \operatorname{Var}(\hat{s})=H_{2} C^{-} H_{2} \delta^{2}
\end{aligned}
$$

Since $\mathbf{H}_{1} \mathbf{1}_{\mathbf{v}}=\mathbf{0}, \mathbf{H}_{2} \mathbf{1}_{\mathbf{v}}=\mathbf{0}, \mathbf{H}_{1} \boldsymbol{H}_{\mathbf{2}}=\mathbf{0}$, we have $\operatorname{rank}\left(\mathbf{H}_{1}\right)=$ p-1 and $\operatorname{rank}\left(\mathbf{H}_{2}\right)=\mathrm{v}-\mathrm{p}$.

It follows that $\mathbf{g}$ and $\mathbf{s}$ are represented by treatment contrasts which carry $\mathrm{p}-1$ and $\mathbf{v}-\mathrm{p}$ degree of freedom, respectively and the contrasts representing $\mathbf{g}$ are orthogonal to those representing $\mathbf{s}$. This means that the proposed design $\mathrm{d}_{3}$ allows for gca and sca effects to be estimated independently. The sum of squares due to gca and sca for design $d$ are given by

$$
\begin{aligned}
& \mathrm{SS}(\text { gca })=\boldsymbol{Q}^{\prime} \mathbf{Z}\left(\mathbf{Z}^{\prime} \mathbf{C}_{\mathbf{d}} \mathbf{Z}\right)^{-} \boldsymbol{Z}^{\prime} \boldsymbol{Q}_{\boldsymbol{d}} \\
& \mathrm{SS}(\text { sca })=\mathbf{Q}_{\mathbf{d}}^{\prime}\left(\mathbf{C}_{\mathbf{d}}^{-}-\mathbf{1} /(\mathbf{p}-\mathbf{2}) \mathbf{Z Z}^{\prime} \mathbf{Q}_{\mathbf{d}}\right.
\end{aligned}
$$

ANOVA is then given in Table 1

Table 1: Analysis of variance for design d

\begin{tabular}{|l|c|l|}
\hline Source of variation & Degrees of Freedom & Sum of squares \\
\hline Block & $\mathrm{p}-2$ & $\mathbf{B}^{\prime} \boldsymbol{B} /(\boldsymbol{p}-\mathbf{1})-\boldsymbol{G}^{\mathbf{2}} / \boldsymbol{p}(\boldsymbol{p}-\mathbf{1})$ \\
\hline Crosses (adjusted for blocks) & $\operatorname{Rank}\left(\mathbf{C}_{\mathrm{d}}\right)$ & $\boldsymbol{Q}_{\boldsymbol{d}}^{\prime} \boldsymbol{C}_{\boldsymbol{d}}^{-} \boldsymbol{Q}_{\boldsymbol{d}}$ \\
\hline gca & $\operatorname{rank}\left(\mathbf{H}_{\mathbf{1}}\right)$ & $\boldsymbol{Q}_{\boldsymbol{d}}^{\prime} \mathbf{Z}\left(\mathbf{Z}^{\prime} \mathbf{C d Z}\right)^{-} \mathbf{Z}^{\prime} \boldsymbol{Q}_{\boldsymbol{d}}$ \\
\hline sca & $\operatorname{rank}\left(\mathbf{H}_{2}\right)$ & $Q^{\prime} \mathbf{Z}\left(\mathbf{Z}^{\prime} \mathbf{C}_{\mathbf{d}} \mathbf{Z}\right)^{-} \mathbf{Z}^{\prime} \boldsymbol{Q}_{\boldsymbol{d}}$ \\
\hline Residual & by subtraction & by subtraction \\
\hline Total & n-1 & $\mathbf{y y}^{\prime}-G^{2} / p(p-1)$ \\
\hline
\end{tabular}

Where $\mathrm{G}=$ grand total of all $\mathrm{n}$ observations

Now we discuss about analysis and optimality of design $\mathrm{d}^{*}$

\section{ANALYSIS AND OPTIMALITY OF DESIGN $d^{*}$}

The data obtained from design $\mathrm{d}^{*}$, we consider the same model as given in equation (3.1)

$$
\mathbf{Y}=\boldsymbol{\mu} \mathbf{1}_{\mathrm{n}}+\mathbf{X} \boldsymbol{\tau}+\mathbf{D} \boldsymbol{\beta}+\mathbf{e}
$$

Where $\mathbf{Y}$ is the $n \times 1$ vector observations, $\mathbf{1}$ is the $n x 1$ vectors of ones, $\mathbf{X}$ is the $n x v$ design matrix for treatments and $\mathbf{D}$ is an nxb design matrix for blocks, that is, the $(h, u)^{\text {th }}\left((\mathrm{h}, \mathrm{I})^{\text {th }}\right.$ elements of $\mathbf{X}$ (respectively, of $\left.\mathbf{D}\right)$ is 1 if the $\mathrm{h}^{\text {th }}$ observations pertains to the $\mathrm{u}^{\text {th }}$ cross (to $\mathrm{i}^{\text {th }}$ block), and is zero otherwise $(\mathrm{h}=1, \ldots, \mathrm{n} ; \mathrm{u}=1, \ldots, \mathrm{v} ;$ and $1, \ldots, \mathrm{b}), \boldsymbol{\mu}$ is a general mean, $\boldsymbol{\tau}$ is a $\mathrm{v} \times 1$ vector of treatment parameters, $\boldsymbol{\beta}$ is $\mathrm{a} b \times 1$ vector of block parameters and $\mathbf{e}$ is an $\mathrm{n}$ 
$\times 1$ vector of residuals. It is assumed that vector $\boldsymbol{\beta}$ is fixed and $\mathbf{e}$ is normally distributed with $\mathrm{E}(\mathbf{e})=0, \mathrm{~V}(\mathbf{e})=\delta^{2} \mathbf{I}$, where $\mathbf{I}$ is the identity matrix of conformable order.

\section{Efficiency Factor}

Now we will show that the design $d$ and $d^{*}$ are optimal in the sense of Kempthorne (1956). If instead of the designs $\mathrm{d}$ and $\mathrm{d}^{*}$, one adopts a randomized complete block design with $\mathrm{r}$ blocks, each block having all the $\mathrm{p}(\mathrm{p}-1) / 2$ crosses, the $\mathbf{C}$ matrix of the randomized block design i.e. can easily be shown to be, see Dey and Midha(1996).

$$
\mathbf{C}_{\mathrm{R}}=\mathrm{r}(\mathrm{p}-2)\left(\mathbf{I}_{\mathrm{p}}-\mathrm{p}^{-1} \mathbf{1} \mathrm{p} \mathbf{1}^{\prime} \mathrm{p}\right)
$$

Hence the variance of the best linear unbiased estimator of any elementary contrast among gca effects in the case of randomized block experiment is $2 \sigma^{2} / \mathrm{r}(\mathrm{p}-2), \sigma^{2}$ is the per observation variance. Thus the efficiency factors $\mathrm{e}_{1}$ and $\mathrm{e}_{2}$, respectively of the design $\mathrm{d}$ and $\mathrm{d}^{*}$, relative to randomized block designs under the assumption of equal intrablock variances are given by

$$
\begin{aligned}
& \mathrm{e}_{1}=\theta / \mathrm{r}(\mathrm{p}-2)=\mathrm{r}(\mathrm{p}-2) / \mathrm{r}(\mathrm{p}-2)=1, \\
& \text { Similarly } \mathrm{e}_{2}=\theta / \mathrm{r}(\mathrm{p}-2)=\mathrm{r}(\mathrm{p}-2) / \mathrm{r}(\mathrm{p}-2)=1 \\
& \text { where } \theta=(\mathrm{p}-2) \text { and } \mathrm{r}=1
\end{aligned}
$$

Furthermore, on the lines of Sharma and Fanta (2010), it can be easily proved that the design $\mathrm{d}^{*}$ are optimal. Now, we are giving the list of practicable useful designs for $5 \leq P \leq 11$ in Table 2

Table 2

\begin{tabular}{|c|c|c|c|c|}
\hline No. & Ref. No of lines & $\begin{array}{c}\text { Number of experimental } \\
\text { units }\end{array}$ & Efficiency factor & Optimality status \\
\hline 1 & 5 & 10 & 1 & Universally Optimal \\
\hline 2 & 6 & 15 & 1 & Universally Optimal \\
\hline 3 & 7 & 21 & 1 & Universally Optimal \\
\hline 4 & 8 & 28 & 1 & Universally Optimal \\
\hline 5 & 9 & 36 & 1 & Universally Optimal \\
\hline 6 & 10 & 45 & 1 & Universally Optimal \\
\hline 7 & 11 & 55 & 1 & Universally Optimal \\
\hline
\end{tabular}

Remarks 1: Designs T33, T34, T77, T84, T94 and T95 were reported by Dey and Midha(1996) as efficient designs. These designs are also optimal in sense of Kempthorne(1956) by our method.

Remarks 2: The design reported in Table 2 belong to series $\mathrm{v}=\mathrm{p}(\mathrm{p}-1) / 2, \mathrm{~b}=\mathrm{p}, \mathrm{r}=2, \mathrm{k}=\mathrm{p}-1, \lambda_{1}=1, \lambda_{2}=0$, Shrikhande(1952) and Bose and Shimamoto(1952). Their duals are reduced BIB designs with parameters $v^{*}=p$, $\mathrm{b}^{*}=\mathrm{p}(\mathrm{p}-1) / 2, \mathrm{r}^{*}=\mathrm{p}-1, \mathrm{k}^{*}=2, \lambda_{1}^{*}=1$. These designs are easy to construct Das and Giri(1986). Hence further optimal design for CDC experiment for 12,13,14 and 15 inbred lines can be obtained by the duals design.

\section{Conclusion}

We have searched some more triangular designs to obtain optimal designs for CDC experiment for comparisons of gca in the presence of sca effects in the model and also in the absence of sca.

\section{References}

Agarwal,S.C. and Das, M.N.(1987). A note on construction and application of balanced n-ary designs. Sankhya, Vol.49, Ser.B, pt 2, pp.192-196

Bose, R.C. and Shimamto (1952). Classification and analysis of partially balanced incomplete block designs. Ann. Math. Statist., 23, 367-383.

Clatworthy (1973). Tables of two-associate class partially balanced designs. National Bureau of Standards, Washinton, D.C. 20234.

Chai, F.S. and Mukerjee,R.(1999). Optimal design for diallel crosses with specific combining abilities. Biometrika, 86(2),453-458.

Chai, F.S. and Mukerjee,R(1999). Optimal design for dial crosses with specific combining abilities. Statistics and probability letters, 57, 145-150

Das, A.; Dey, A. and Dean, A. (1998). Optimal design for diallel cross experiments. Statist., Prob. Letters, 36, 427-436.

Dey, A. and Midha, Chand, K. (1996). Optimal designs for diallel crosses. Biometrika, 81, 484-489.

Das,M.N. and Giri,N,C,(1986). Design and analysis of experiments. Wiley Eastern Limited, New Delhi ,India.

Dey, A.(1986). Theory of block designs. Wiley Eastern, New Delhi.

Dey,A and Midha,C.K.(1996). Optimal designs for dialllel crosses.

Gupta, S. and Kageyama, S. (1994). Optimal complete diallel crosses. Biometrika, 81, 420-424.

Griffing, B. (1956). Concept of general specific combining ability in relation to diallel crossing systems. Aust. J. Biol. Sci. 9, 463-93. 
Kiefer, J. (1975). Construction and optimality of generalized Youden designs. In A survey of Statistical Design and Linear Models, Ed. J.N. Srivastava, pp. 33-53. Amesterdam: North Hollond

Kempthorne,O. (1956). The theory of diallel crosses. Genetics 41,451-459

Kempthorne,O and Curnow. R.N(1961). The partiall dialllel cross. Biometrics 17, 229-250 \{ see also corrections, Biometrics 18(1962), 128$\}$

Mukerjee, R. (1997). Optimal partial diallel crosses. Biometrika, 84(4), 937-946.

Parsad, R.; Gupta, V.K. and Srivastava, R. (1999). Optimal designs for diallel crosses. Jour. Soc. Stat., Comp. and Application, Vol. 1, 35-52.

Parsad, R.; and Gupta, V.K.(2004): Optimal designs for diallel cross experiments: An overview. (Chapter 1), Dhanpat Rai \&Co. (P)Ltd., N. Delhi

Parsad, R., Gupta, V.K., and Gupta, S. (2005). Optimal Designs for Diallel and Double Cross Experiments. Utilitas, Mathematica, 68,11-32.

Raghavarao, D.(1971), construction and combinatorial problems in design of Experiments. J. Wiley and sons, New York.

Rao, C $>$ R.(1973). Linear statistical inference and its applications, $2^{\text {nd }}$ edition. J. Wiley and sons, New York.

Sharma, M.K. (2004). Optimal complete diallel cross.Advances in Mating Designs (Chapter 15), Dhanpat Rai \&Co. (P)Ltd., N. Delhi.

Sharma, M.K. and Fanta, Sileshi (2010). Optimal block designs for diallel crosses. Metrika, 71, 361-372

Shrikhande, S.S. (1952). On the dual of some balanced incomplete designs. Biometrics, 8, 66-72.

Signh,M and Hinkelmann,K.(1998). Analysis of partial diallel crosses in incomplete blocks. Biometrical journal, 40, $165-182$.

Tocher, K.D.(1952). The design and analysis of block experiments(with discussion).J. Royal.statist. soc., B, 14, 45-100 